\title{
Endoscopic-Assisted Infralabyrinthine Approach to Petrous Apex Cholesterol Granuloma
}

\author{
Gina $\mathrm{Na}^{1}$, Sohi $\mathrm{Bae}^{2}$, Jeon Mi Lee ${ }^{3}$, and In Seok Moon ${ }^{1}$ \\ ${ }^{I}$ Departments of Otorhinolaryngology, ${ }^{2}$ Radiology, Yonsei University College of Medicine, Seoul; and \\ ${ }^{3}$ Department of Otorhinolaryngology, Ilsan Paik Hospital, Inje University College of Medicine, Goyang, Korea
}

\author{
내시경 보조하에 제거한 추체 첨부의 콜레스테롤 육아종 1 예 \\ 나지나 ${ }^{1} \cdot$ 배소희 $^{2} \cdot$ 이전미 $^{3} \cdot$ 문인석 $^{1}$ \\ 연세대학교 의과대학 이비인후과학교실, ${ }^{1}$ 영상의학교실, ${ }^{2}$ 인제대학교 의과대학 일산백병원 이비인후과학교실 ${ }^{3}$
}

\author{
Received April 24, 2017 \\ Revised June 19,2017 \\ Accepted June 28, 2017 \\ Address for correspondence \\ Jeon Mi Lee, MD, PhD \\ Department of Otorhinolaryngology, \\ Ilsan Paik Hospital, Inje University \\ College of Medicine, \\ 170 Juhwa-ro, Ilsanseo-gu, \\ Goyang 10380, Korea \\ Tel $+82-31-910-7114$ \\ Fax $+82-31-910-7518$ \\ E-mail entmeowmiya@gmail.com
}

A cholesterol granuloma is the most common primary lesion of the petrous apex, and accounts for $40 \%$ of the pathologies that arise in this region. The primary treatment for symptomatic lesions is by surgery to decompress and drain or to completely remove the lesion. Here we describe the use of infralabyrinthine approach to access a lesion through the temporal bone and completely remove it with the assistance of a 0 -degree endoscope. A 43-year-old man visited our clinic for diplopia. Magnetic resonance imaging revealed a $2.3-\mathrm{cm}$ cholesterol granuloma located in the left petrous apex that caused deviation of the left abducens nerve. The tumor was completely removed using the endoscopic-assisted infralabyrinthine approach; the patient is currently being followed up, and there is no evidence of disease recurrence. This case report describes the successful completion of a petrous apex cholesterol granuloma that preserved the cochlear and vestibular systems. Korean J Otorhinolaryngol-Head Neck Surg 2019;62(1):60-3

Key Words Abducens palsy $\cdot$ Cholesterol granuloma $\cdot$ Endoscopic-assisted Petrous apex tumor.

\section{서 론}

콜레스테롤 육아종(cholesterol granuloma)는 추체 첨부 (petrous apex)에서 발생하는 가장 흔한 병변으로, 많게는 이 구역에서 발생하는 종물의 $40 \%$ 를 차지한다. ${ }^{1)}$ 콜레스테롤 육아종은 독립적인 질환을 지칭하는 것이 아닌 콜레스테롤 결절에 대한 조직의 이물질 반응으로 발생하는 육아조직을 일컫는 비특이적인 조직병리학적 소견이며, ${ }^{2)}$ 중이, 유양동 및 추체 첨부 등 측두골의 함기조직 어느 부위에서나 발생할 수 있는 것으로 알려져 있다. ${ }^{3)}$ 측두골에서 발생한 콜레스테롤 육아종은 대부분 증상을 야기하지 않는 것으로 알려져 있지만,
크기가 큰 경우 뇌신경 증상이나 난청, 이명 등의 증상을 동반 할 수 있다. 증상이 없이 우연히 발견된 경우에는 특별한 치료 를 필요로 하지 않지만, 증상을 동반하는 경우에는 수술적 치 료를 통하여 병변 주위를 감압하고 내용물을 배액하여 병변 을 제거하고 재발을 막는 과정이 필요하다. 지금까지 추체 첨부 의 콜레스테롤 육아종을 제거하기 위하여 다양한 접근 방법 이 제시되었는데, 최근 내시경의 발달로 좀 더 덜 침습적이고 주변 구조물을 보존할 수 있는 방법들이 소개되고 있다.

본 저자들은 미로하 내시경 보조 접근법으로 추체 첨부의 콜레스테롤 육아종을 제거한 증례보고를 통해 수술 방법 및 술 후 결과를 문헌 고찰과 함께 보고하는 바이다.

This is an Open Access article distributed under the terms of the Creative Commons Attribution Non-Commercial License (https://creativecommons.org/licenses/by-nc/4.0) which permits unrestricted non-commercial use, distribution, and reproduction in any medium, provided the original work is properly cited. 


\section{증 례}

43세 남자가 한 달 전부터 시작된 복시를 주소로 내원하였 다. 환자는 좌측을 주시할 때 심해지는 복시 외에는 두통, 어 지럼증 및 청력 저하, 이명, 이통 등 다른 증상을 호소하지 않
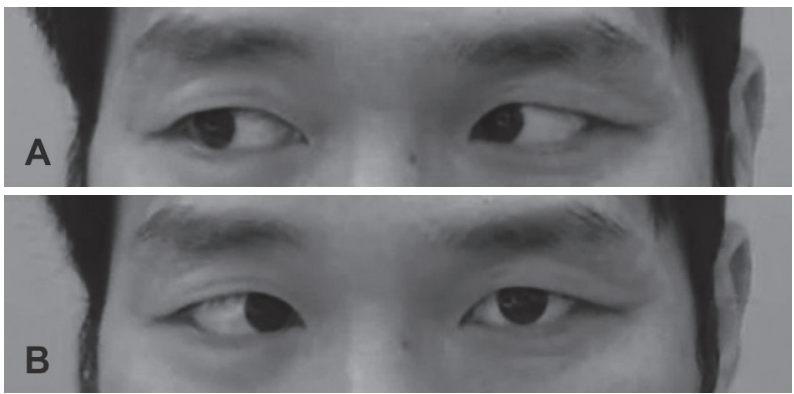

Fig. 1. Preoperative eyeball movements. Eyeball movements were correct when the patient looked to the right (A). When the patient looked to the left, the left eye showed limited abduction, and the patient reported diplopia (B).
았다. 환자는 고혈압 외 다른 과거력은 없었다. 신체검사에서 좌측 안구의 외전이 제한되어 있었으며(Fig. 1), 양측 고막을 포 함한 다른 신체 부위에서 이상 소견을 보이지 않았다. 순음청 력검사에서 양측 모두 정상 소견을 보였으며, 온도안진검사 에서 반고리관 마비 소견은 관찰되지 않았다. 측두 자기공명 영상에서 좌측 추체 첨부에 약 $2.3 \mathrm{~cm}$ 크기의 종물이 확인되 었으며, 종물은 T1, T2 강조 영상에서 고신호를 보였지만 T1 가돌리늄 조영 강조 영상에서 조영되지 않고 감소된 신호를 보 여 콜레스테롤 육아종을 의심할 수 있는 소견을 보였다(Fig. $2 \mathrm{~A})$. 또한 좌측 외전신경의 cisternal segment가 종물에 의하 여 눌려 있는 소견이 확인되었다(Fig. 2B).

위의 결과를 토대로 본 의료진은 추체 첨부의 콜레스테롤 육아종 제거 수술을 계획하였다. 술 전 환자의 청각 및 전정 기 능은 정상으로, 최대한 구조물을 보존하며 병변을 제거할 수 있 도록 내시경을 이용한 미로하 접근법을 계획하였다(Fig. $3 \mathrm{~A}$ ).

좌측 후이개 영역에 피부 절개 후 단순 유양동삭개술을 시행

Fig. 2. Preoperative MRI. MRI revealed an expansile tumor approximately $2.3 \mathrm{~cm}$ in size in the left petrous apex, suggesting a cholesterol granuloma (A). The cisternal segment of the left abducens nerve was stretched due to the tumor (arrowheads) (B). MRl: magnetic resonance image.
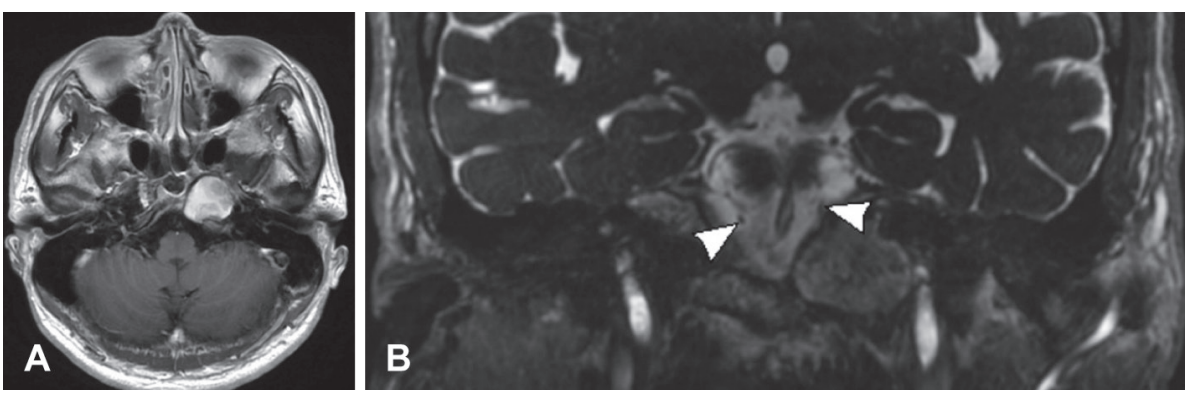

Fig. 3. The planned approach to the tumor. Arrow indicates the direction of the approach (A). The infralabyrinthine area was drilled through to expose the epithelial wall of the tumor (circle) (B). SS: sigmoid sinus, JB: jugular bulb, FN: facial nerve, CA: carotid artery, DR: digastric ridge, I: incus, LSC: lateral semicircular canal, PSC: posterior semicircular canal.
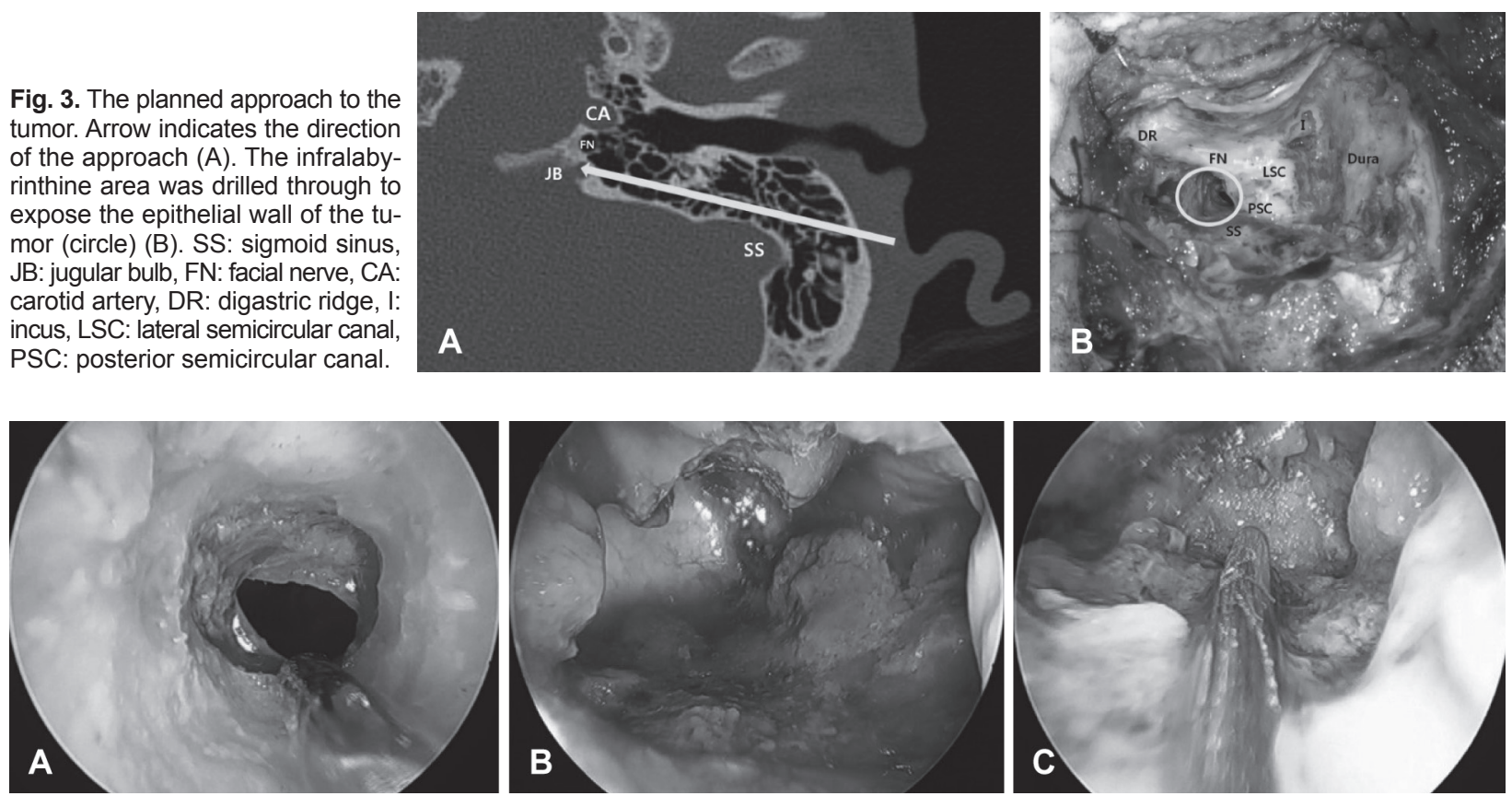

Fig. 4. The surgical views of endoscopic-assisted tumor removal. The torn epithelial wall of the tumor as seen in the endoscopic view (A). Brown fluid and debris were visible inside the tumor (B). The internal contents were removed, and the epithelial wall was carefully removed from the dura $(\mathrm{C})$. 
하였다. 넓은 수술 시야를 확보하기 위하여 유돌첨(mastoid tip)은 제거하였다. 안면신경, 가쪽 반고리관 및 뒤쪽 반고리 관, 중두개와 경막과 sigmoid 정맥동, 이복능 등 기준점들을 확 보하고 경계를 설정하였다. 경계는 상방으로는 뒤쪽 반고리관, 하방으로는 경정맥구(jugular bulb), 내측으로는 속목동맥(internal carotid artery), 외측으로는 sigmoid 정맥동으로, 각 구 조물이 다치지 않도록 주의를 기울여 드릴과 rongeur forcep 을 이용해 조심스럽게 골 조직을 제거하여 종물의 외측 벽을 노출하였다(Fig. 3B). 종물의 외측 벽을 노출시킨 후에는 $3 \mathrm{~mm}$ 직경의 $0^{\circ}$ 내시경(KARL STORZ GmbH\&Co.KG, Tuttingen, Germany)을 이용하여 종물에 접근하였다. Sickle knife를 이 용하여 종물의 벽을 뚫자 종물의 내부에서 잔해를 포함한 갈색의 점성이 높은 액체가 흘러나왔으며, 수차례 종물의 내 부를 세척하여 시야를 확보하였다. 내시경을 이용해 종물의 내 부로 접근하여 조심스럽게 경막에서 종물의 상피성 벽을 분리 하여 모두 제거하였다(Fig. 4). 이 과정 중 경막이 일부 손상되 면서 뇌척수액이 누출되는 소견을 보여, 조심스럽게 경막을 봉 합하고 fibrin-collagen patch(TachoComb, Nycomed, Zurich, Switzerland)을 덧대어 뇌척수액의 누출을 방지하였다. 이후 더 이상 남아 있는 병변이 없음을 확인한 뒤 수술을 종료하 였다. 술 후 보고된 조직병리검사에서 콜레스테롤 육아종이 확인되었다.

수술 다음 날 촬영한 자기공명영상에서 콜레스테롤 육아종 이 완전히 제거되었으며 유양동까지 배액로(drainage track) 가 잘 형성된 것을 확인할 수 있었다(Fig. 5). 술 후 1 주일에 합 병증 없이 환자는 퇴원하였으며, 술 후 2 달째 환자의 좌측 안 구의 움직임은 정상화되었다. 환자는 주기적인 신체검사 및 영상검사를 통하여 추적관찰 중이며, 아직까지 재발의 증거 는 보이지 않는다.

\section{고 찰}

콜레스테롤 육아종은 추체 첨부에서 나타나는 가장 흔한 병변으로, 대부분의 경우 무증상이며 우연히 영상검사에서 발견되는 경우가 많다. 콜레스테롤 육아종에 의한 증상은 대 부분 내이 및 중이 구조물이나 뇌신경 등 주변 조직을 압박함 으로써 발생하며 난청, 두통, 이명, 또는 어지럼증 등을 야기할 수 있다. ${ }^{4}$ 최근 보고된 논문에 의하면 추체 첨부의 콜레스테 롤 육아종으로 인하여 증상을 호소하는 환자 중 반 이상은 두통을, 그리고 $1 / 3$ 에서 어지럼증을 호소한다고 알려져 있다. 그에 비하면 안면 감각 이상(12.2\%), 감각신경성 난청(6.7\%), 안 면 마비(2.2\%) 등은 비교적 드문 것으로 알려져 있으며, 특히 복시(1.1\%)는 매우 드물게 보고된다. ${ }^{5)}$ 복시는 외전신경의 마 비로 인하여 발생하게 되는데, 마비의 원인은 여러 가지로 추 정된다. 그중 하나는 뇌신경으로의 혈류 장애로, 혈관 위험인 자가 높은 환자들에서 복시의 발생 빈도가 높으며,') 대부분 3 개월 이내에 자연 회복된다는 근거가 있다. ${ }^{7)}$ 본 증례에서는 다른 증상 없이 복시가 첫 증상으로 나타났으며 자기공명영 상에서 종물에 의하여 외전신경이 눌려 있는 소견이 확인되었 던 드문 증례로, 일시적 혈류 장애와는 다르게 증상의 호전을 위해서는 반드시 수술적 치료가 필요했던 경우이다.

종물이 계속 자라나거나 증상이 발생할 경우에는 치료의 대상이 되는데 이때 치료는 외벽과 내용물을 포함하여 종물 을 완전 절제하거나, 혹은 주변을 둘러싸고 있는 구조물들을 감압하여 콜레스테롤 육아종을 배액하고, 병변을 환기시키는 방법이 있다. ${ }^{8)}$ 종물을 완전 절제할 경우 재발이 적은 대신 수 술 중 주변 조직을 손상시킬 우려가 있으며, 감압 및 배액은 접 근이 비교적 용이하다는 장점이 있지만 재발의 가능성이 높 다." 추체 첨부의 콜레스테롤 육아종의 경우 접근 및 시야의 한계가 존재하기 때문에 종물을 완전 제거하기보다는 배액 후 배액관을 유치하여 재발을 방지하는 방법을 비교적 더 많

Fig. 5. Postoperative MRI revealed a well-formed drainage track from the petrous apex to the mastoid cavity with complete removal of the tumor contents. Preoperative MRI (A). MRI performed 1 day postoperation (B). MRI: magnetic resonance imaging.
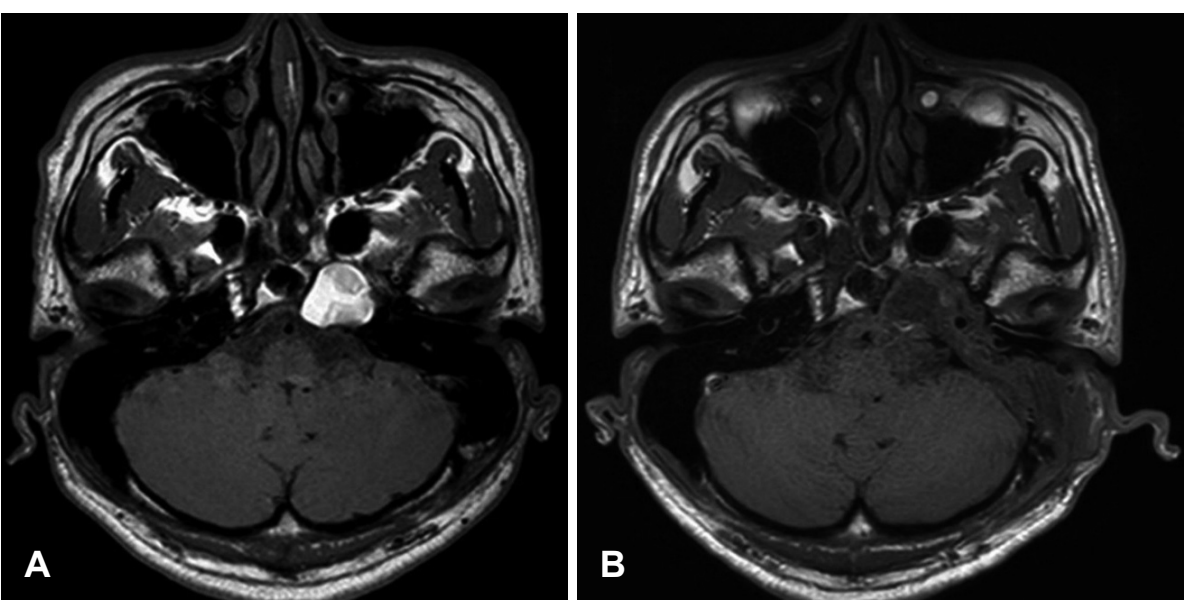
이 선호한다. 그럼에도 불구하고 종물의 위치적 특성 때문에, 주변 구조물을 완전히 보존하면서 종물에 접근하는 것은 어 려운 일이다.

2004년 Mattox ${ }^{9}$ 는 처음으로 기존의 수술용 현미경을 기반 으로 한 접근법에 내시경을 추가로 도입하여 성공적으로 추 체 첨부의 콜레스테롤 육아종을 배액하여 치료하였다. 그는 손상 시 치명적인 혈관과 신경이 존재하는 좁은 부위에 내시 경을 도입함으로써 시야를 확보하기 위한 불필요한 시술 과 정을 없애고, 모니터를 통해 병변 및 주위 구조물을 정확하게 확인함으로써 제한된 공간에서 주요 구조물들을 보존하면서 도 안전하게 병변을 제거할 수 있었다. 이러한 장점을 이유로 이과 영역에서 내시경 접근법의 범위는 점차 넓어지는 추세이 다. 내시경을 이용한 고막 성형술이나 이소골 성형술 등의 중 이수술은 이미 현미경 접근법과 비슷하거나 더 좋은 결과를 보고하고 있으며, ${ }^{10,11)}$ 두개저수술에도 내시경을 도입하여 성공 적인 결과를 이끌어 내고 있다. ${ }^{12)}$ 진주종을 비롯한 추체 첨부 의 병변을 제거하는 데에도 본 증례처럼 현미경과 내시경을 모두 이용하여 성공적으로 병변을 제거한 증례가 많이 보고되 고 있을 뿐 아니라, ${ }^{9,13)}$ 현미경을 사용하지 않고 외이도를 통하 여 내시경만으로 병변을 제거하는 술기도 이루어지고 있다. ${ }^{14)}$

그러나 이처럼 괄목할 만한 성장에도 불구하고 콜레스테 롤 육아종은 여전히 재발의 위험에서 벗어나지 못하며, 배액 후 배액관을 유치했던 10 명의 환자 중 6 명에서 종물이 재발된 예가 보고된 적도 있다. ${ }^{15)}$ 추체 첨부의 콜레스테롤 육아종의 경우 재발 후 재수술의 위험도나 난이도가 처음부터 종물을 완전 절제하는 것보다 낮기 때문 ${ }^{9)}$ 에 여전히 완전 절제보다는 감압 및 배액법을 선호하는 것으로 알려져 있다. 본 증례에 서는 수술용 현미경을 이용하여 병변에 접근한 뒤 내시경을 이용하여 경막과 종물의 외벽을 분리하여 종물을 완전 절제 할 수 있었다. 비록 그 과정 중 경막 손상이 있어 봉합 및 뇌 척수액 누수를 보완하는 과정이 필요했지만, 장기적인 관점에 서 재발을 방지할 수 있는 장점이 있었다고 생각된다.

본 증례에서는 현미경과 내시경의 동시 접근법을 이용하여 추체 첨부의 콜레스테롤 육아종을 제거하고 증상을 치료하였 다. 병변의 성격과 위치를 고려하여 최소 침습적인 방법으로
접근하여 복시를 회복한 증례로, 내시경을 이용하여 종물을 완전 절제하고 재발 가능성을 낮출 수 있었다. 이를 토대로 향 후 추체 첨부의 콜레스테롤 육아종을 포함한 다양한 측두골 질환의 치료에 있어 내시경의 활용 가능성을 넓힌 좋은 예가 될 것으로 생각한다.

\section{REFERENCES}

1) Lo WW, Solti-Bohman LG, Brackmann DE, Gruskin P. Cholesterol granuloma of the petrous apex: CT diagnosis. Radiology 1984;153 (3):705-11.

2) Gherini SG, Brackmann DE, Lo WW, Solti-Bohman LG. Cholesterol granuloma of the petrous apex. Laryngoscope 1985;95(6):659-64.

3) Jaisinghani VJ, Paparella MM, Schachern PA, Le CT. Tympanic membrane/middle ear pathologic correlates in chronic otitis media. Laryngoscope 1999;109(5):712-6.

4) Gore MR, Zanation AM, Ebert CS, Senior BA. Cholesterol granuloma of the petrous apex. Otolaryngol Clin North Am 2011;44(5):1043-58.

5) Sweeney AD, Osetinsky LM, Carlson ML, Valenzuela CV, Frisch CD, Netterville JL, et al. The natural history and management of petrous apex cholesterol granulomas. Otol Neurotol 2015;36(10):1714-9.

6) Chi SL, Bhatti MT. The diagnostic dilemma of neuro-imaging in acute isolated sixth nerve palsy. Curr Opin Ophthalmol 2009;20(6):423-9.

7) Sanders SK, Kawasaki A, Purvin VA. Long-term prognosis in patients with vasculopathic sixth nerve palsy. Am J Ophthalmol 2002;134 (1):81-4.

8) Brackmann DE, Toh EH. Surgical management of petrous apex cholesterol granulomas. Otol Neurotol 2002;23(4):529-33.

9) Mattox DE. Endoscopy-assisted surgery of the petrous apex. Otolaryngol Head Neck Surg 2004;130(2):229-41

10) Bennett ML, Zhang D, Labadie RF, Noble JH. Comparison of middle ear visualization with endoscopy and microscopy. Otol Neurotol 2016; 37(4):362-6

11) Migirov L, Yakirevitch A, Wolf M. The utility of minimally invasive transcanal endoscopic approach for removal of residual/recurrent cholesteatoma: preliminary result. Eur Arch Otorhinolaryngol 2015; 272(11):3241-6.

12) Wang ZY, Jia H, Yang J, Tan HY, Wu H. A combination use of endoscope and microscope in cerebral pontine angle surgery. Zhonghua Er Bi Yan Hou Tou Jing Wai Ke Za Zhi 2017;52(2):85-8.

13) Carlton DA, Iloreta AM, Chandrasekhar SS. Endoscopic-assisted transmastoid decompression of petrous apex cholesterol granuloma. Laryngoscope 2017;127(2):496-9.

14) Wick CC, Hansen AR, Kutz JW Jr, Isaacson B. Endoscopic infracochlear approach for drainage of petrous apex cholesterol granulomas: a case series. Otol Neurotol 201;38(6):876-81.

15) Thedinger BA, Nadol JB Jr, Montgomery WW, Thedinger BS, Greenberg JJ. Radiographic diagnosis, surgical treatment, and long-term follow-up of cholesterol granulomas of the petrous apex. Laryngoscope 1989;99(9):896-907. 